\title{
Acute Morphogenic and Chemotropic Effects of Neurotrophins on Cultured Embryonic Xenopus Spinal Neurons
}

\author{
Guo-li Ming, Ann M. Lohof, and James Q. Zheng \\ Department of Neuroscience and Cell Biology, University of Medicine and Dentistry of New Jersey, Robert Wood \\ Johnson Medical School, Piscataway, New Jersey 08854
}

\begin{abstract}
Neurotrophins constitute a family of trophic factors with profound effects on the survival and differentiation of the nervous system. Addition of brain-derived neurotrophic factor (BDNF) or neurotrophin-3 (NT-3), but not nerve growth factor (NGF), increased the survival of embryonic Xenopus spinal neurons in culture, although all three neurotrophins enhanced neurite outgrowth. Here we report that neurotrophins also exert acute actions on the morphology and motility of 1-day-old cultured Xenopus spinal neurons. Bath application of BDNF induced extensive formation of lamellipodia simultaneously at multiple sites along the neurite shaft as well as at the growth cone. The
\end{abstract}

BDNF-induced lamellipodia appeared within minutes, rapidly protruded to their greatest extent in about $10 \mathrm{~min}$, and gradually disappeared thereafter, leaving behind newly formed thin lateral processes. When applied as microscopic concentration gradients, both BDNF and NT-3, but not NGF, induced the growth cone to grow toward the neurotrophin source. Our results suggest that neurotrophic factors, when delivered to responsive neurons, may serve as morphogenic and chemotropic agents during neuronal development.

Key words: growth cone; lamellipodium; turning; chemotropism; actin; neurotrophic factors
The development and maintenance of the nervous system depend on the presence of neurotrophic factors, which include retrograde factors derived from postsynaptic target cells, proteins secreted from presynaptic neurons, and molecules released from glial and hematopoietic cells (Barde, 1989). Neurotrophins constitute a family of growth factors that includes nerve growth factor (NGF), brain-derived neurotrophic factor (BDNF), neurotrophin-3 (NT3), NT-4/5, and NT-6 (Barbacid, 1995; Ip and Yancopoulos, 1995). A large number of studies have demonstrated an important role for neurotrophins in proliferation, differentiation, and survival of nerve cells in both central and peripheral nervous systems (for review, see Barde, 1990; Davies, 1994; Klein, 1994; Snider, 1994). In addition to these trophic effects on the nervous system, recent studies have revealed a number of novel biological actions of neurotrophins. In particular, neurotrophins can profoundly influence synaptic connections in developing and adult nervous systems, both functionally and structurally (for review, see Lo, 1995; Thoenen, 1995; Berninger and Poo, 1996). The finding that the expression of some neurotrophins is activity-dependent (Ernfors et al., 1991; Isackson et al., 1991; Lu et al., 1991; Patterson et

Received May 29, 1997; revised Aug. 1, 1997; accepted Aug. 5, 1997.

Part of this study (bath application) was performed at the Marine Biological Laboratory (MBL; Woods Hole, MA), with the support of a Stephen W. Kuffler and MBL associates summer fellowship (1995) to J.Q.Z. We thank Dr. George M. Langford (Dartmouth College, Hanover, NH) for hosting J.Q.Z. during his summer stay at MBL. We express gratitude to Ms. Jean Gibney for technical assistance, Dr. Florence Frederic (Institut des Neurosciences, Université Pierre et Marie Curie, Paris, France) for help with statistics, Dr. Mu-ming Poo (University of California at San Diego, La Jolla, CA) for his advice on the experiments, and Dr. Ira Black for his review and comments on this manuscript.

Correspondence should be addressed to Dr. James Q. Zheng, Department of Neuroscience and Cell Biology, University of Medicine and Dentistry of New Jersey, Robert Wood Johnson Medical School, 675 Hoes Lane, Piscataway, NJ 08854.

Ms. Ming's present address: Department of Biology, University of California at San Diego, 9500 Gilman Drive, La Jolla, CA 92093.

Dr. Lohof's present address: Laboratoire de Neurobiologie, Ecole Normale Supérieure, 46 rue d'Ulm, 75005 Paris, France.

Copyright (C) 1997 Society for Neuroscience $0270-6474 / 97 / 177860-12 \$ 05.00 / 0$ al., 1992; Funakoshi et al., 1993) suggests a possible role for neurotrophins in activity-dependent regulation of synapse development.

One key activity of neurotrophins is to promote neurite outgrowth of sensitive neuronal populations (for review, see Snider and Johnson, 1989; Kuffler, 1994; Lundborg et al., 1994), although some inhibitory effects of neurotrophins on neurite growth have also been observed (Griffin and Letourneau, 1980; Zhang et al., 1994). Cohen-Cory and Fraser (1995) showed that Xenopus retinal axons in vivo responded within $2 \mathrm{hr}$ to exogenous BDNF with persistent increases in branching complexity, suggesting a role for neurotrophins in axonal growth and branching. Another potential function of neurotrophins in early neuronal development is to act as target-derived diff usible factors to guide axon growth. There is considerable recent evidence in vivo and in cell culture indicating that growth cones are guided to target cells in part by chemotropism, i.e., by gradients of attractants diffusing from intermediate or final target cells (for review, see Kennedy and Tessier-Lavigne, 1995; Tessier-Lavigne and Goodman, 1996). A chemoattractive effect of NGF was demonstrated in vitro (Letourneau, 1978; Gundersen and Barrett, 1980) as well as in vivo (Menesini-Chen et al., 1978), although later studies argued against an in vivo role of NGF in long-range axonal guidance during development (Lumsden and Davies, 1983; Davies et al., 1987), mainly because of the late expression of NGF in the target. On the other hand, both BDNF and NT-3 are expressed much earlier during development (Maisonpierre et al., 1990; Hallböök et al., 1993), suggesting that they could be candidates for a role in early stages of axonal growth and guidance.

In the present study, we have examined the acute effects of several neurotrophins on the neurite morphology and motility of Xenopus spinal neurons in culture. We first established that neurotrophins affect the neuronal survival and neurite outgrowth of cultured Xenopus spinal neurons. We then show that BDNF acutely induced extensive lamellipodial activity simultaneously at 
multiple sites along neurite shafts and at the growth cone, leading to modification of neurite morphology. Finally, we demonstrate that a diffusible gradient of NT-3 or BDNF induced a positive turning response of Xenopus growth cones toward the source of the neurotrophin, whereas a similar gradient of NGF had no effect. Our results suggest that neurotrophins may play important roles in morphological development and pathfinding of developing neurons.

\section{MATERIALS AND METHODS}

Cell culture. Cultures were prepared according to procedures reported previously (Spitzer and Lamborghini, 1976; Tabti and Poo, 1990). In brief, the neural tube tissue from developing embryos at stages 20-22 (Nieuwkoop and Faber, 1967) was dissociated in a $\mathrm{Ca}^{2+}$ - and $\mathrm{Mg}^{2+}$-free Ringer's solution supplemented with EDTA (in mM: $115 \mathrm{NaCl}, 2.5 \mathrm{KCl}$, 10 HEPES, and 0.5 EDTA, pH 7.6), plated on clean glass coverslips, and incubated at room temperature $\left(20-22^{\circ} \mathrm{C}\right)$. The culture medium consisted of $50 \%(\mathrm{v} / \mathrm{v})$ Leibovitz medium (Life Technologies, Gathersburg, MD), $1 \%(\mathrm{v} / \mathrm{v})$ fetal bovine serum (Life Technologies), and $49 \%(\mathrm{v} / \mathrm{v})$ Ringer's solution (in mM: $115 \mathrm{NaCl}, 2 \mathrm{CaCl}_{2}, 2.5 \mathrm{KCl}$, and $10 \mathrm{HEPES}$, $\mathrm{pH}$ 7.4). All experiments were performed at room temperature.

Neurotrophins and chemicals. Human recombinant NGF (rHu-NGF), NT-3 (rHu-NT-3), and BDNF (rHu-met-BDNF) were generously provided by Regeneron Pharmaceuticals, Inc. (Tarrytown, NY). All neurotrophins were aliquoted at $10 \mathrm{mg} / \mathrm{ml}$ and stored at $-85^{\circ} \mathrm{C}$. Working stock solutions of $100 \mu \mathrm{g} / \mathrm{ml}$ were prepared and used within 1 week. Neurotrophins at working concentrations were prepared before each experiment. K252a was purchased from Research Biochemicals International (Natick, MA). Cytochalasin B was purchased from Sigma (St. Louis, MO).

Assay for neuronal survival and neurite outgrowth. In experiments on neuronal survival, neurotrophins were added to the cultures at the time the cells were plated. The neurite-bearing neurons were counted daily for the first $6 \mathrm{~d}$ after plating. A cell was considered a neuron if it had a small soma and neurite processes of uniform diameter that were at least $20 \mu \mathrm{m}$ long. It is important to note, therefore, that our study is limited to neurite-bearing neurons. If these cultures contained neurons without neurites, or if some neurons retracted their neurites during the course of the experiment, they would not have been identified. It is thus possible that our survival analysis is complicated by issues of neurite maintenance. However, in these cultures, active neurite outgrowth was normally observed within the first day after plating. After $1 \mathrm{~d}$ in culture, most non-neuronal cells (e.g., muscle cells and fibroblasts) have become spread in shape and are readily distinguishable from neurons that have small, round somas bearing long neurite processes. Cells with small somas (i.e., putative neurons) lacking neurites were rarely seen after $1 \mathrm{~d}$ in culture, and a neuronal soma and its neurites were usually observed to degenerate at the same time. Therefore, our quantification of neuritebearing cells after $1 \mathrm{~d}$ in culture should closely represent the survival of neurons.

For experiments on neurite outgrowth, neurotrophins were added to cultures on the day of plating, and neurons were examined $24 \mathrm{hr}$ later The experiments were performed on a Nikon TMS inverted microscope equipped with phase-contrast optics and a $20 \times$ objective. The images of individual neurons were acquired through a $1 / 3$ inch CCD video camera (Coordinated Systems, Inc., East Hartford, CT), digitized by a SNAPPY video digitizer (Play Inc., Ranco Cordova, CA), and analyzed by using the ImageTool program [developed at the University of Texas Health Science Center at San Antonio (UTHSCSA), San Antonio, TX; available from the Internet by anonymous file transfer protocol from ftp:// maxrad6.uthscsa.edu]. The lengths of neurite processes were measured by tracing the entire trajectory of neurite extension, including all branches.

Bath application of neurotrophins and acute morphogenic effects. Cells from 1-day-old cultures grown on a glass coverslip were mounted on a microscopy chamber using silicon vacuum grease (Dow Corning, Midland, MI) and visualized on a Nikon Diaphot 300 inverted microscope equipped with differential interference contrast (DIC) optics. A $1 / 2$ inch CCD video camera was used in conjunction with an Argus-20 image processor (Hamamatsu Photonics, Inc.). The video images were background-subtracted, averaged over four frames, and contrastenhanced in real time. The video images were then recorded at a standard rate of one frame every $5 \mathrm{sec}$ on a Panasonic TQ-2026F optical disk recorder (Matsushita Electric Industrial Co., Ltd.) controlled by a personal computer. For each experiment, 5 min of control recording was performed before the addition of neurotrophins. Neurotrophins at their final working concentrations were applied to the culture by rapid perfusion of the culture medium. Immediately after the perfusion, 10-20 min of time-lapse recording at the standard rate was performed.

To analyze lamellipodia formation quantitatively, the recorded timelapse DIC images were played back frame by frame, and individual frames were captured, digitized, and acquired by a Gateway P5-133 computer with the aid of the Argus-20 image processor. The numbers and sizes (area) of individual lamellipodia at different time points were then quantified using the UTHSCSA ImageTool program. We considered a neuron to be responsive to neurotrophins when it showed an increase in the number and size $\left(>100 \mu \mathrm{m}^{2}\right)$ of lamellipodia after the addition of neurotrophins.

Production of microscopic gradients. Microscopic concentration gradients of neurotrophins were produced by repetitive pulsatile ejection of solutions containing neurotrophins through a glass micropipette according to a method described previously (Lohof et al., 1992; Zheng et al., 1994, 1996). The glass micropipettes were pulled with a two-stage pipette puller designed for making patch-clamp electrodes (PP-83; Narishige, Tokyo, Japan) and heat-polished on a microforge (Narishige MF-83) to reduce the inner diameter of the tip to $\sim 1 \mu \mathrm{m}$. The pipettes were filled with the neurotrophin solution and connected to an electrically gated pressure application system (Picospritzer; General Valve, Fairfield, NJ). Positive pressure of 3 psi was applied to the pipette at a frequency of 2 $\mathrm{Hz}$ and a pulse duration of $20 \mathrm{msec}$ using a pulse generator (SD9; Grass Instruments, Quincy, MA).

Chemotropic test. Most experiments on growth cone turning were performed on a Nikon TMS inverted microscope equipped with phasecontrast optics. The direction of neurite extension at the beginning of the experiment was defined by the distal $20 \mu \mathrm{m}$ segment of the neurite. The pressure ejection pipette tip was positioned $45^{\circ}$ from the initial direction of extension and $100 \mu \mathrm{m}$ away from the center of the phase-dark "palm" of the growth cone. Microscopic images of neurons at various times after the onset of the neurotrophin gradient were acquired by a CCD video camera and recorded on a videotape recorder. For quantification of neurite extension and turning, the trajectory of each neurite was traced from the video images, and the final position of the growth cone at the end of $1.5 \mathrm{hr}$ experimental period was determined in polar coordinates, with the origin set at the position of the growth cone at the onset of the gradient. The turning angle and net extension of the neurite for each case were measured using a digitizing tablet (Hipad; Houston Instruments, Houston, TX). The turning angle was defined by the angle between the original direction of neurite extension and a line connecting the position of the growth cone at the experiment onset and at the end of $1.5 \mathrm{hr}$ exposure to the gradient. The length of neurite extension was obtained by measuring the length of the entire trajectory of the path of the neurite growth over the $1.5 \mathrm{hr}$ period. In the cases of high-resolution DIC imaging, the experiments were performed on a Zeiss inverted microscope equipped with an imaging system consisting of a cooled CCD camera (STAR I; Photometrics, Tucson, AZ) and a personal computer running Windows-based imaging software written by J.Q.Z. (ZStar for Windows; available at web site http://www2.umdnj.edu/ zhengjq/). The images of the neuron were directly acquired into the computer, digitally stored, and analyzed. We define growth cones with turning angles greater than $5^{\circ}$ as positive turning (turning toward the pipette), smaller than $-5^{\circ}$ as negative turning (turning away from the pipette), and between $-5^{\circ}$ and $5^{\circ}$ as no turning.

\section{RESULTS}

\section{Effect of neurotrophins on survival of Xenopus spinal neurons}

Different neurotrophins are known to promote the survival of distinct but overlapping neuronal populations (Lewin and Barde, 1996, and references therein). Under the minimal culture conditions used in these experiments (see Materials and Methods), most embryonic Xenopus spinal neurons survive just over $2 \mathrm{~d}$. To test whether the neurotrophins affect neuronal survival, $50 \mathrm{ng} / \mathrm{ml}$ rHu-met-BDNF, rHu-NT-3, or rHu-NGF was added to the culture medium at the time of cell plating, and the number of neurite-bearing cells was counted for the next $6 \mathrm{~d}$ (see Materials and Methods for scoring criteria). Figure $1 a$ shows the proportion 


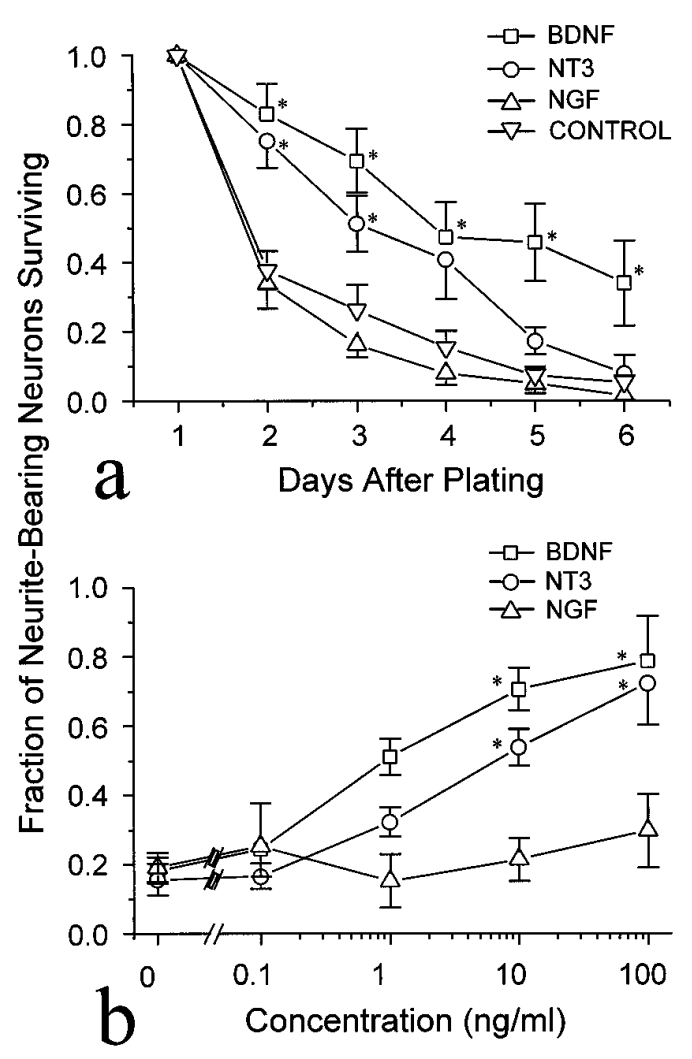

Figure 1. Neuronal survival increased in the presence of NT-3 or BDNF. The number of neurite-bearing neurons was normalized to the number present at $24 \mathrm{hr}$ after plating. Each point represents the mean \pm SEM of three experiments. $a$, BDNF, NGF, or NT-3 (each $50 \mathrm{ng} / \mathrm{ml}$ ) was added to cultures on the day of plating, and cells were counted daily. Only BDNF and NT-3 enhanced the survival. $b$, Dose dependency of the survival effect. Different concentrations of neurotrophins were added to cultures on the day of plating; the number of neurite-bearing neurons remaining on the third day of culture was normalized to the number present at $24 \mathrm{hr}$ after plating. ${ }^{*}$ Significantly different from control $(p<$ 0.05 , Kruskal-Wallis test).

of neurite-bearing cells remaining in cultures treated with different neurotrophins compared with that in untreated control cultures. In control cultures and in cultures treated with NGF, $\sim 40 \%$ of the neurite-bearing neurons present on day 1 remained on day 2. The presence of BDNF or NT-3 in the culture increased that percentage to $80 \%$, and the difference in survival was detectable throughout the $6 \mathrm{~d}$ period.

The dose dependencies of the BDNF and NT-3 effects on the survival of neurite-bearing neurons were determined by treating cultures with different concentrations of the factors. Figure $1 b$ shows the proportion of neurite-bearing cells remaining on day 3 in cultures treated with different doses of NT-3, BDNF, or NGF. The effective neurotrophin concentrations are similar to those previously shown to enhance the synaptic activity of these neurons (Lohof et al., 1993) and similar to doses that promote survival in other neuronal populations (Hyman et al., 1991; Segal et al., 1992), although for some neuronal types much lower doses are effective (Henderson et al., 1993).

\section{Effect of neurotrophins on neurite outgrowth}

To examine the effects of neurotrophins on the extent of neurite outgrowth during the first day of culture, $50 \mathrm{ng} / \mathrm{ml} \mathrm{rHu-met-}$ BDNF, rHu-NT-3, or rHu-NGF was added to cultures at the time of cell plating. Twenty-four hours later, the total neurite lengths

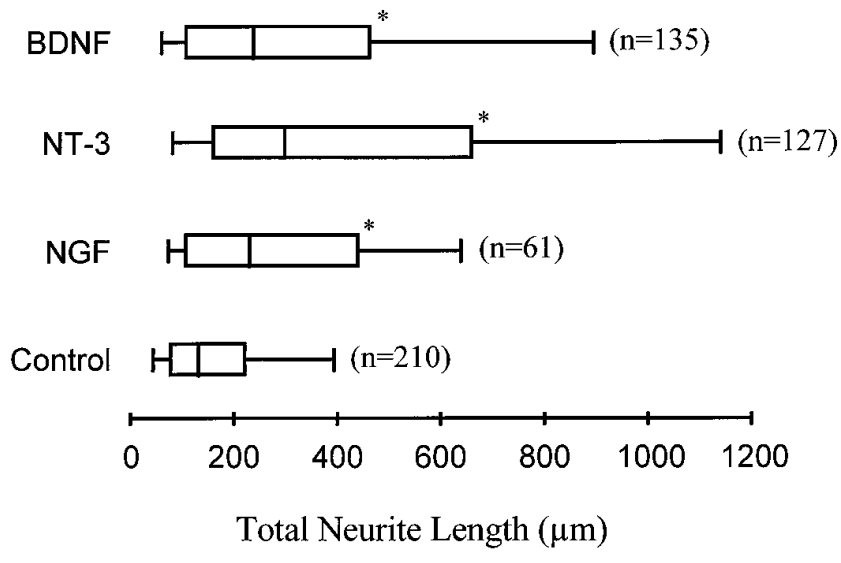

Figure 2. Enhanced neurite outgrowth in the presence of neurotrophins. Neurotrophins (at $50 \mathrm{ng} / \mathrm{ml}$ ) were added to the cultures at the time of cell plating, and the total neurite lengths including all branches were measured $24 \mathrm{hr}$ later. Results were collected from three separate experiments. Because the total neurite lengths did not follow a normal distribution, the data are present as box and whisker plots. The boxes enclose the 25 th and 75 th percentiles of the distributions; the median is marked by the vertical lines, and the error bars denote the 10th and 90th percentiles. All three neurotrophins (NGF, BDNF, and NT-3) increased the total neurite lengths compared with untreated neurons $\left({ }^{*} p<0.001\right.$, Kruskal-Wallis test) but with different effectiveness.

of neurons (including branches) in treated and untreated cultures were measured from at least three separate experiments. The neurite lengths did not follow a normal distribution; therefore, the data are presented as box and whisker plots (Fig. 2). All three neurotrophins promoted neurite outgrowth, NT-3 being the most effective. The median total neurite lengths for NGF, NT-3, and BDNF are 230, 297, and $237 \mu \mathrm{m}$, respectively, which are significantly longer than the median $(132 \mu \mathrm{m})$ of parallel control $(p<$ 0.001 , Kruskal-Wallis test). The outgrowth-promoting effects were not uniform on all cultured spinal neurons, as indicated by the largely expanded distribution of total neurite lengths in neurotrophin-treated cultures (Fig. 2). Although the neurite lengths at 90th percentile $(637,1141$, and $894 \mu \mathrm{m}$ for NGF, NT-3, and BDNF, respectively) are much longer than that of the control $(392 \mu \mathrm{m})$, the neurite lengths at the 10th percentile are close between treated and untreated cultures $(47,75,85$, and $61 \mu \mathrm{m}$ for control, NGF, NT-3, and BDNF, respectively). Furthermore, an overlap in the distribution of total neurite lengths between treated and untreated cultures was observed, suggesting the existence of less-responsive populations of neurons. The existence of subpopulations with different responsiveness to different neurotrophins is consistent with a similar observation of the effects on synaptic activity in these neurons (Lohof et al., 1993). Moreover, in other neuronal types, similar subpopulations exist, which selectively transport or respond to different neurotrophins (Ruit et al., 1992).

\section{Acute effects of neurotrophins on the morphology of neurons}

Studies were performed on $24 \mathrm{hr}$ cultures, in which most spinal neurons have extended considerable length of neurite processes $(>100 \mu \mathrm{m})$ and have started to arborize to display distinctive morphology (Fig. 3). This is essential for the morphological studies. Unlike cultures at $6-10 \mathrm{hr}$ after plating in which spinal neurons exhibit active neurite outgrowth and growth cones with numerous motile filopodia (Fig. 3a), neurons in $24 \mathrm{hr}$ cultures 


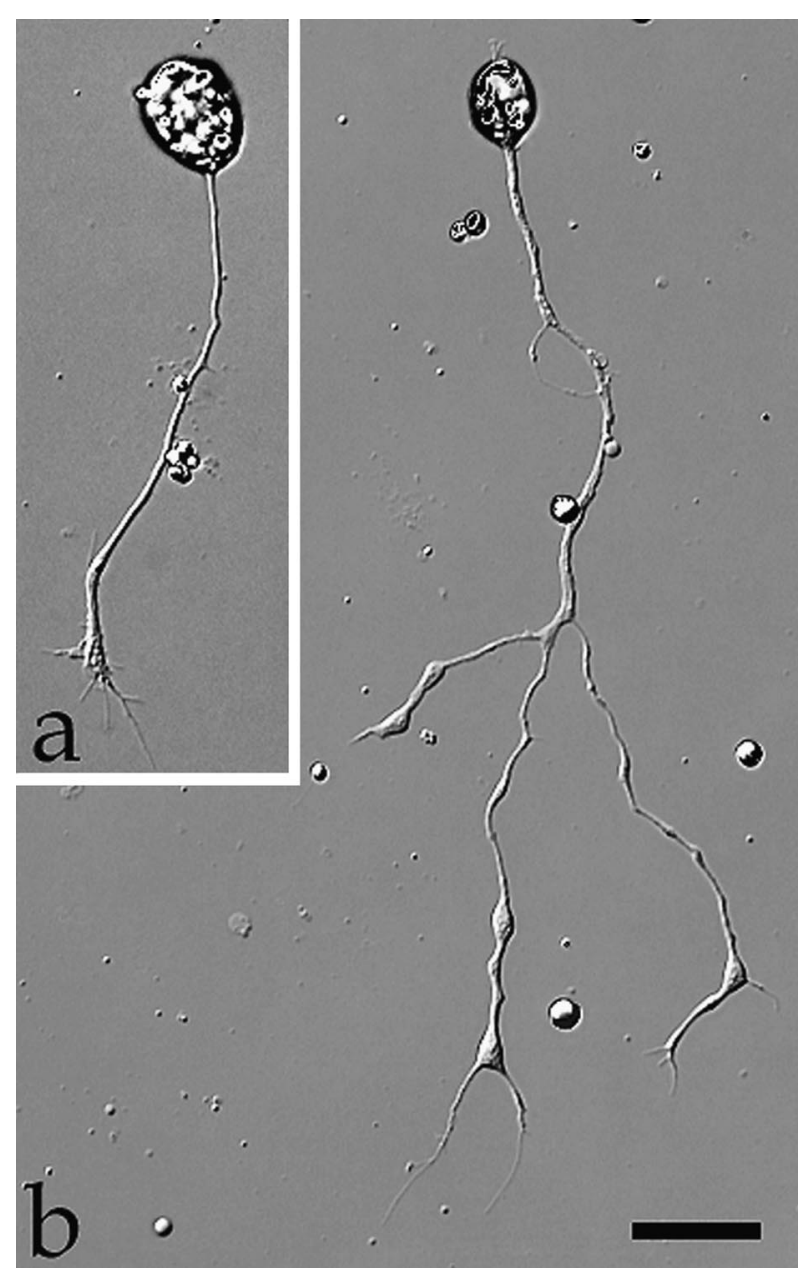

Figure 3. Representative images of cultured Xenopus spinal neurons at 8 hr $(a)$ or $24 \mathrm{hr}(b)$ after plating. Note the more elaborated neurite development of the older neuron. Scale bar, $30 \mu \mathrm{m}$.

display less-motile growth cones with reduced numbers of filopodia (Fig. 3b). Nonetheless, neurite extension in $24 \mathrm{hr}$ cultures was still observed at a rate of about $10 \mu \mathrm{m} / \mathrm{hr}$, slower than in $6 \mathrm{hr}$ cultures ( $\sim 15 \mu \mathrm{m} / \mathrm{hr}$ ) (also see Zheng et al., 1996).

To test the acute effects of neurotrophins on the morphology of cultured Xenopus spinal neurons, we used high-resolution DIC time-lapse imaging to examine the changes before and after the addition of neurotrophins. Time-lapse imaging was performed at a standard rate of one image every $5 \mathrm{sec}$; cells were first monitored for $5 \mathrm{~min}$ before the medium was replaced with neurotrophin-containing medium by rapid perfusion. A $10 \mathrm{~min}$ period of time-lapse imaging was normally conducted immediately after the perfusion to record neurotrophin-induced changes. Within 2-3 min after the application of $50 \mathrm{ng} / \mathrm{ml} \mathrm{BDNF}$, new lamellipodia were formed at multiple sites along the neurite shaft as well as at the growth cone (Fig. 4a, arrows). Like lamellipodia observed in many other motile cells (Bray and White, 1988) and in some nerve growth cones (Smith, 1988), BDNFinduced lamellipodia exhibited two characteristic types of motility: protrusive activity and retrograde membrane ruffling. Quantitative measurement showed that these BDNF-induced lamellipodia rapidly protruded and grew in size over the $10 \mathrm{~min}$ period in a near-linear manner (Fig. 4b). Prolonged time-lapse recordings showed that most BDNF-induced lamellipodial activ- ity persisted over the next 10-20 min and gradually decreased after $30 \mathrm{~min}$. Although both BDNF and NT-3 enhanced neuronal survival in a similar dose-dependent manner, only BDNF effectively induced lamellipodia formation when acutely applied. When NT-3 or NGF (each at $50 \mathrm{ng} / \mathrm{ml}$ ) was acutely applied, only a small proportion of neurons responded by forming lamellipodia (Fig. 5). The BDNF-induced lamellipodial activity apparently depended on the activation of high-affinity Trk receptors, because it was blocked by 200 nм K252a (Fig. 5), a relatively selective and potent inhibitor for Trk kinases (Knusel and Hefti, 1992; Tapley et al., 1992).

The core structure of lamellipodia is the actin cytoskeleton, which is assembled into a meshwork in lamellipodia (Small et al., 1982). Using fluorescence staining with rhodamine-phalloidin, we determined that the formation of lamellipodia induced by BDNF involves rapid polymerization of the actin cytoskeleton (Fig. 6a,b). In the absence of BDNF treatment, actin filaments were concentrated mainly in the growth cone, whereas a thin layer of cortical actin meshwork was observed beneath the plasmalemma in the neurite shaft (Smith, 1988; Zheng et al., 1996). The rapid formation of lamellipodia along the neurite shaft produced by bath application of BDNF was accompanied by the polymerization of the actin cytoskeleton (Fig. 6a,b). Application of cytochalasin $\mathrm{B}$, a fungal metabolite that is known to inhibit the polymerization of the actin cytoskeleton, completely blocked the lamellipodia formation induced by BDNF (Fig. 6c), suggesting that the actin cytoskeleton is the target for the BDNF action.

One unique feature of BDNF-induced lamellipodia is that these lamellipodia were very mobile, because they were able to translocate along neurite branches. This is evident in Figure 7, in which two BDNF-induced lamellipodia (Fig. 7d, arrows) moved rapidly along neurite branches. The lamellipodium on the upper left branch came down to the branching junction, merged with the branch on the upper right side, and went up again. The other lamellipodium moved from the left to the right and disappeared at the other branching junction. Such lamellipodial activity also affected the morphology and branching pattern of the neurites. As shown in Figure 7, two upper branches eventually merged after the lamellipodial activity (arrowheads). More interestingly, an increased number of thin lateral processes emerged from the main processes (Fig. $7 d$, outlined in $e, f$ ) after the lamellipodial activity. Whether these thin lateral processes can develop into mature branches is unknown.

\section{Chemotropic response of growth cones to neurotrophins}

Pathfinding of the nerve growth cone during development depends on the turning of growth cones in response to a variety of extracellular cues. As a motile structure leading the extending neurite processes, the growth cone determines the rate and direction of neurite extension, which is closely associated with filopodia and lamellipodial activity at the growth cone (Sato et al., 1994; Tanaka and Sabry, 1995; Mason and Wang, 1997). Because acute bath application of BDNF induced active lamellipodial protrusion at the growth cone as well as along the neurite shaft, we tested the ability of neurotrophins to affect the direction of neurite growth when applied as concentration gradients using a procedure we developed previously (Lohof et al., 1992; Zheng et al., 1994). A concentration gradient of various neurotrophins was created by repetitive ejection of neurotrophin-containing solution from a micropipette (see Materials and Methods). Previous theoretical estimates (Lohof et al., 1992) and quantitative measure- 

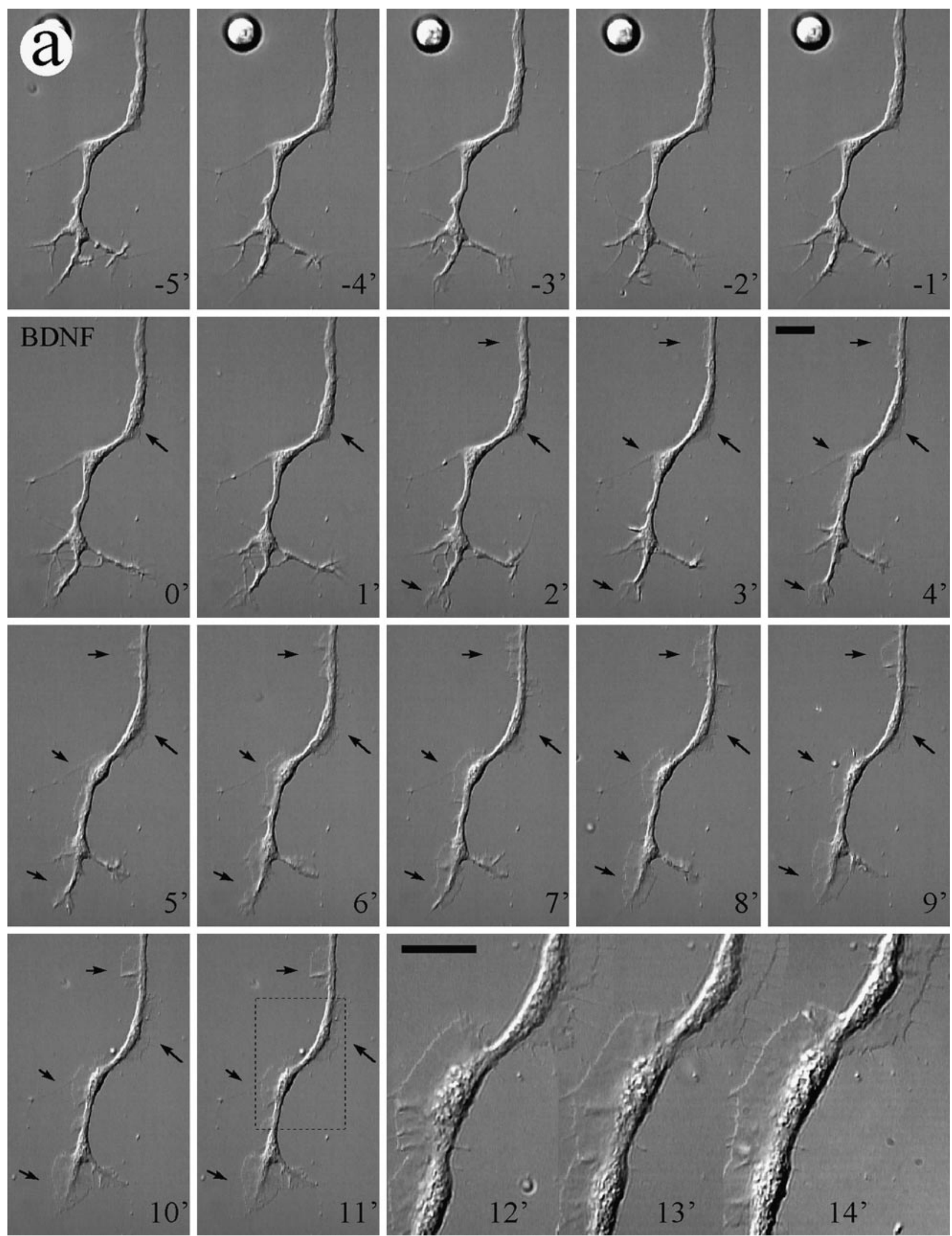

Figure 4. Lamellipodia formation induced by bath application of BDNF. $a$, A DIC time-lapse sequence showing the morphological changes on a 24 hr cultured Xenopus neuron induced by BDNF. Numbers represent minutes. BDNF ( $50 \mathrm{ng} / \mathrm{ml})$ was added to the culture by perfusion at time 0 . During the control period (negative numbers), no substantial lamellipodial activity was observed. Immediately after the application of BDNF, lamellipodia started to appear at multiple sites along the neurite shaft as well as at the growth cone (arrows). At 11 min after the addition of BDNF, one portion of the neuron (outlined by the dashed box) was viewed at higher magnification. Scale bars, $25 \mu \mathrm{m}$. $b$, Quantitative measurement (area) of BDNF-induced lamellipodia (indicated by the arrows in $a$ ) shows the dynamics of the rapid protrusion of these lamellipodia over the first 10 min of observation. Figure continues. 


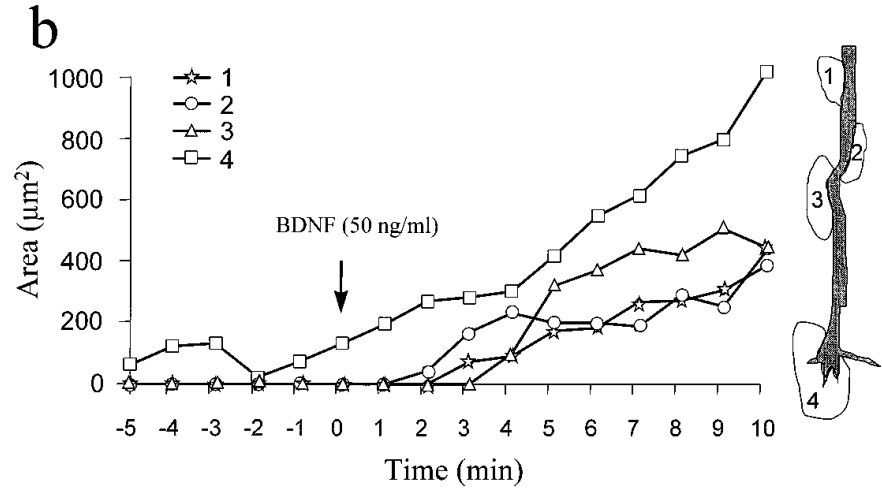

Figure 4 Continued.

ments (Zheng et al., 1994) have shown that a stable gradient of $\sim 10-12 \%$ over a distance of $10 \mu \mathrm{m}$ (approximately the width of the growth cone) is established during the repetitive pulse application. As shown in Figure $8 a$, pulsatile application of medium containing $50 \mu \mathrm{g} / \mathrm{ml} \mathrm{NT}-3$ caused the growth cone to grow toward the pipette, which was defined as a positive turning response. We examined the effects of three neurotrophins (NGF, NT-3, and $\mathrm{BDNF}$ ) on the turning of the growth cone. To illustrate better the turning behavior of the growth cone, composite tracings of the trajectory of the neurite extension during the $1.5 \mathrm{hr}$ period are shown in Figure $8 b$. Although, as expected, not all neurons responded to the neurotrophin gradient positively, a significantly greater number of growth cones grew toward the source of 50 $\mu \mathrm{g} / \mathrm{ml} \mathrm{BDNF}(n=11)$ or $50 \mu \mathrm{g} / \mathrm{ml} \mathrm{NT}-3(n=16)$. In contrast, growth cones exposed to culture medium only $(n=17)$ or 50 $\mu \mathrm{g} / \mathrm{ml} \mathrm{NGF}(n=12)$ showed similar frequencies of turning toward and away from the source. At $100 \mu \mathrm{m}$ from the source, the average background concentration of neurotrophin is $\sim 10^{3}$-fold lower than that in the pipette (see Lohof et al., 1992). Therefore, the concentration of NT-3 or BDNF reaching the growth cone would be $50 \mathrm{ng} / \mathrm{ml}$, an effective concentration for neuronal survival and lamellipodia induction (see above).

To quantify the turning response, turning angle and neurite extension were measured during the $1.5 \mathrm{hr}$ experimental period (Zheng et al., 1994, 1996) (see Materials and Methods). The results of all the growth cones exposed to culture medium alone or medium containing various neurotrophins at three different concentrations are summarized in Table 1. ANOVA and post hoc Dunnett's tests showed that gradients produced by $50 \mu \mathrm{g} / \mathrm{ml}$ pipette concentrations of BDNF and NT-3 produced turning angles significantly greater than controls $(p<0.05)$. No significant difference in net neurite extension between different groups was observed. The turning produced by BDNF and NT-3 appeared, qualitatively, to be dose-dependent (compare mean turning angles for BDNF at $50 \mathrm{vs} 5 \mu \mathrm{g} / \mathrm{ml}$, for example), although no statistically significant dose effect could be demonstrated. Growth cones exposed to NGF gradients behaved no differently from controls. The average angles for all the three concentrations of NGF were near zero, similar to the turning angles for culture medium control as well as the low concentration BDNF and NT-3 groups. These results demonstrate that neurotrophins BDNF and NT-3, but not NGF, exhibit chemoattractive effects on the growth cone of developing Xenopus spinal neurons.

\section{DISCUSSION}

The central findings of this report are the novel acute effects of neurotrophins on cultured embryonic Xenopus spinal neurons:

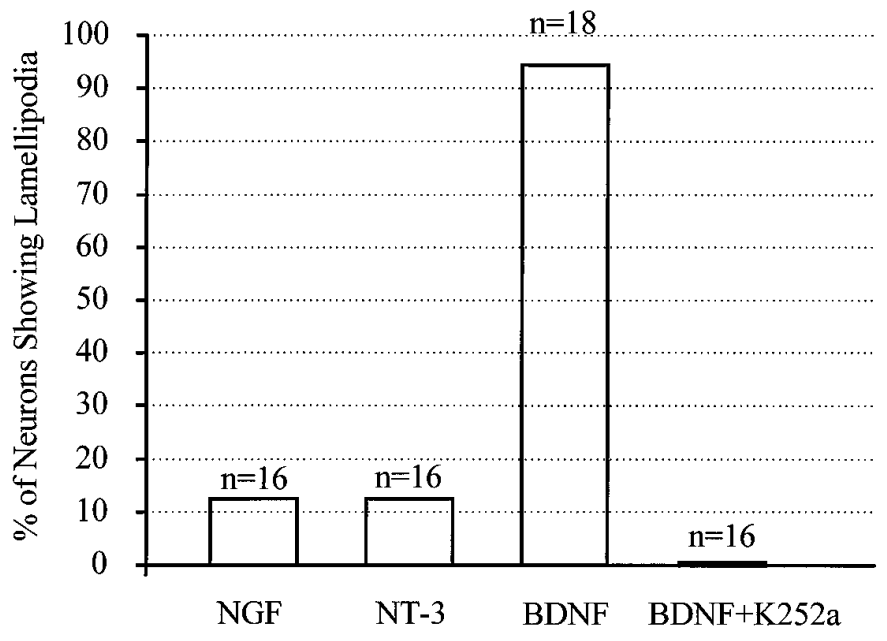

Figure 5. Summary showing the percentages of cells with increased lamellipodial activity after neurotrophin application. Each cell was monitored for $5 \mathrm{~min}$ before and $10 \mathrm{~min}$ after the addition of neurotrophins by time-lapse imaging. A neuron was considered responsive when it showed an increase in the number and size $\left(>100 \mu \mathrm{m}^{2}\right)$ of lamellipodia after the neurotrophin addition.

extensive lamellipodial activity along neurite processes and chemoattractive guidance of nerve growth cones. These effects, if occurring in vivo, could play an important role in the formation and remodeling of neuronal circuitry during development.

\section{Neurotrophin effects on neuronal survival and neurite outgrowth}

The enhancement on neuronal survival in these cultures by NT-3 or BDNF is consistent with the classical role of neurotrophic factors as neuronal survival factors during development. The effective doses of BDNF and NT-3 are similar to those shown to affect synaptic activity of these neurons and survival in other neuronal populations (Hyman et al., 1991; Segal et al., 1992) but higher than the concentrations that promote survival of, for example, mouse motor neurons (Henderson et al., 1993). One possible explanation is that the recombinant human neurotrophins used in this study may not activate the Xenopus Trk receptors optimally. Activation of specific Trk receptor tyrosine kinases is believed to mediate most of the biological effects of the neurotrophins (for review, see Chao, 1992; Barbacid, 1994; Dechant et al., 1994). Although the neurotrophins themselves are highly conserved between species (Hallböök et al., 1991), the degree of conservation between the mammalian and Xenopus Trk receptors is not known.

Application of neurotrophins also promoted the neurite outgrowth of these cultured Xenopus neurons. Although this effect was observed for all three neurotrophins, NT-3 was most effective (Fig. 2). The expanded distribution of total neurite length in neurotrophin-treated cultures and the overlap observed in the distribution of total neurite lengths between treated and untreated cultures suggest that not all of the neurons responded to neurotrophins with increased neurite outgrowth. Given the heterogeneity of the Xenopus cultures, it is unsurprising that subpopulations of neurons may show different responses. The effects on neurite outgrowth are unlikely to have been complicated by the survival effects, because the neurite lengths were measured before the time when most neuronal degeneration takes place in these cultures. Furthermore, the fact that NGF did not enhance 

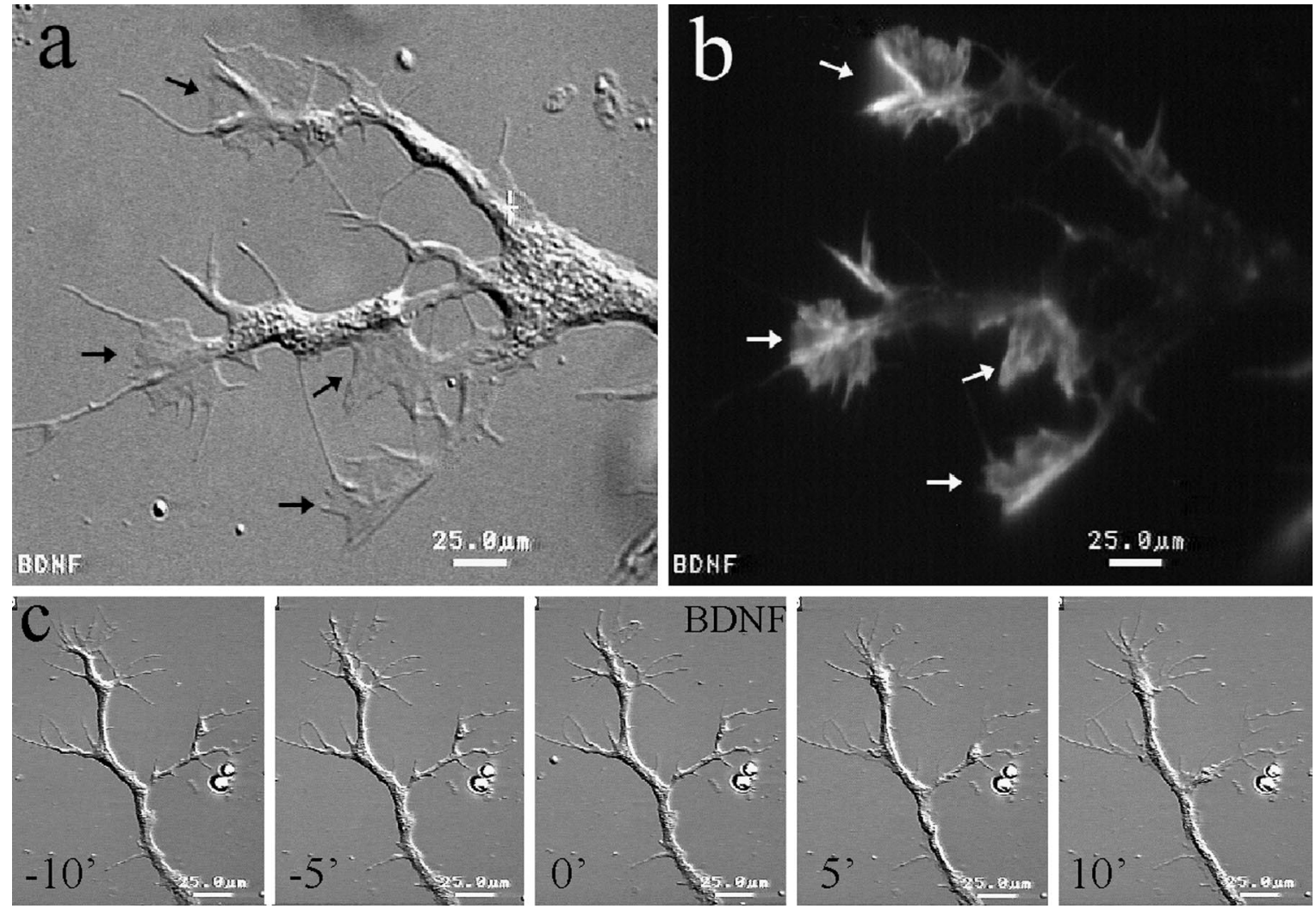

Figure 6. BDNF-induced lamellipodial activity requires actin polymerization. $a, b$, Fluorescent image of a BDNF-treated neuron stained by rhodamine-phalloidin shows concentrated actin-filaments $(b$, white arrows) at the BDNF-induced lamellipodia, as seen in the corresponding DIC image (a, black arrows). c, Cytochalasin B (5 $\mu \mathrm{M})$ completely blocked the lamellipodial activity induced by BDNF, as demonstrated by the time-lapse sequence. Scale bars, $25 \mu \mathrm{m}$.

survival but did increase neurite outgrowth suggests that the effects on survival and neurite outgrowth are separate events.

\section{Lamellipodial activity induced by BDNF}

Lamellipodia are motile structures primarily found at the leading edge of motile cells and nerve growth cones. Previous studies showed that in cultures of sympathetic neurons and PC12 cells, withdrawal of NGF resulted in the loss of lamellipodial and filopodial activity and the inhibition of neurite extension. Readdition of NGF rapidly restored the growth cone motility, including the formation of filopodia and lamellipodia at the growth cone as well as a transient microspike activity along the neurite shaft (Seeley and Greene, 1983; Connolly et al., 1985, 1987; Aletta and Greene, 1988). Here we report that BDNF induced extensive lamellipodial activity not only at the growth cone but also at numerous locations along the neurite shaft of neurons. The rapidity of the response is reminiscent of the NGF-induced morphological changes in NGF-deprived sympathetic neurons, but no acceleration of neurite extension was observed. The BDNFinduced lamellipodia exhibited all the characteristic features observed in migrating cells and nerve growth cones: highly dynamic protrusion and retrograde membrane ruffling. This effect was completely blocked by K252a, suggesting the involvement of Trk receptor tyrosine kinases. Activation of Trk receptor tyrosine kinases is known to elicit a range of second messenger responses, including increases in intracellular $\mathrm{Ca}^{2+}$, cAMP, cGMP, and phosphoinositide turnover, as well as to activate the protein kinases Src and Raf and the GTP-binding protein Ras (for reviews, see Heumann, 1994; Kaplan and Stephens, 1994; Greene and Kaplan, 1995; Segal and Greenberg, 1996). Calcium has been shown to be involved in the regulation of growth cone motility (Kater and Mills, 1991) and is implicated in the synaptic potentiation induced by acute application of BDNF (Stoop and Poo, 1996). However, our preliminary studies showed that lamellipodia can still be induced by BDNF in a $\mathrm{Ca}^{2+}$-free solution (data not shown), suggesting that extracellular $\mathrm{Ca}^{2+}$ is not required for this effect.

Although the intracellular signaling cascade leading to the formation of lamellipodia induced by BDNF is currently unknown, it is clear that the process involves the reorganization of the actin cytoskeleton (Fig. 6). Previous studies on growth factorinduced membrane ruffling in non-neuronal cells suggested that phosphatidylinosital-3 (PI-3) kinase and the Ras-related GTPbinding protein Rac are directly involved in the actin rearrangement required for membrane ruffling (Wennstrom et al., 1994; Barker et al., 1995; Kotani et al., 1995; Parker, 1995). Activation of Trk receptor tyrosine kinases by neurotrophins also activates PI-3 kinases (Ohmichi et al., 1992; for review, see Kaplan and Stephens, 1994); whether PI-3 kinase and Rac are involved in BDNF-induce lamellipodial activity remains to be elucidated.

One potential function for BDNF-induced lamellipodia formation is to remodel the neurite branching pattern and, possibly, their synaptic connections. Long-term changes in synaptic function are often associated with structural modification of the synapse (Desmond and Levy, 1986; Bailey and Chen, 1988; Glanzman et al., 1990; Bailey and Kandel, 1993), and structural changes in synaptic connection are likely to alter synaptic functions. 

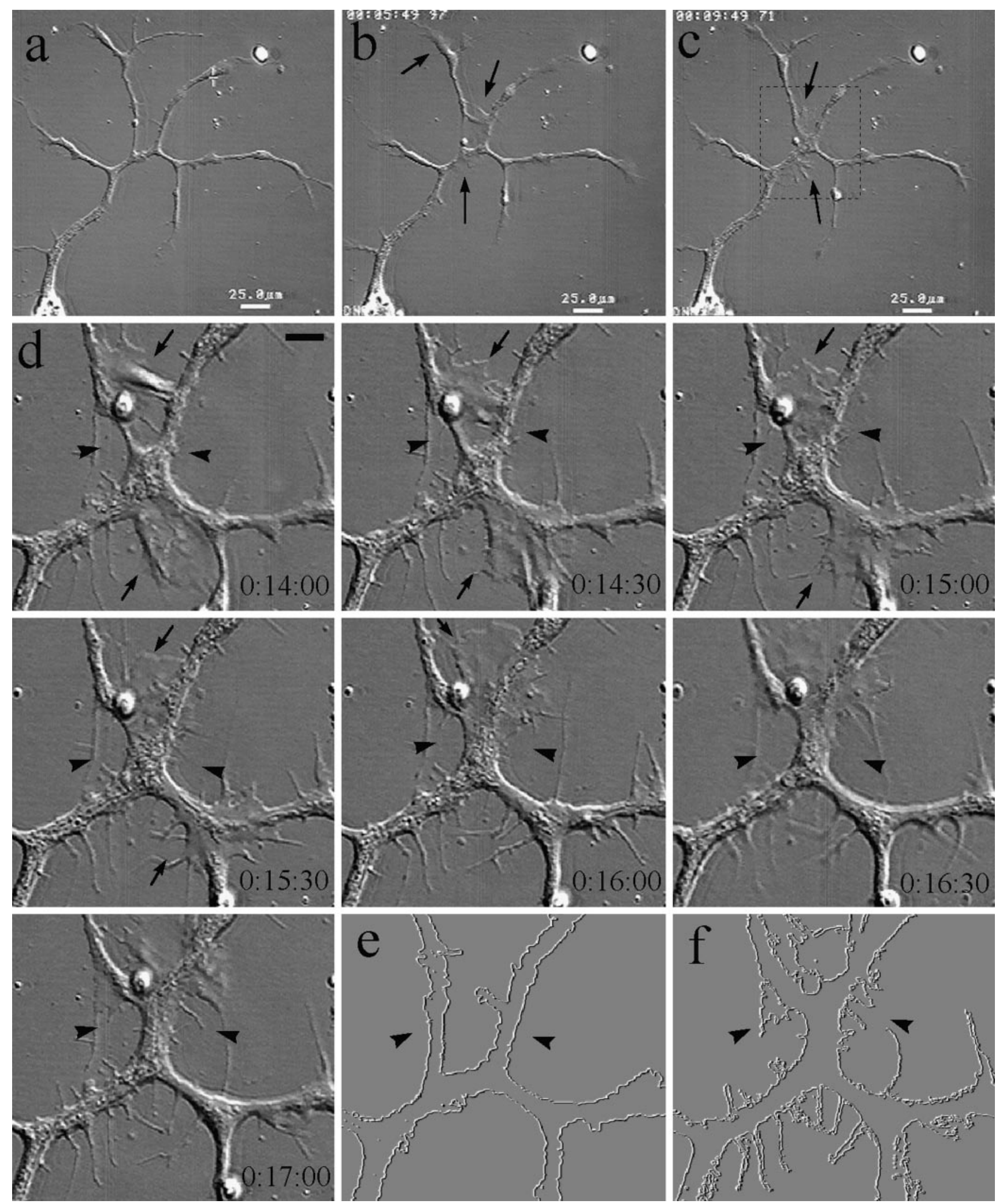

Figure 7. Dynamics of BDNF-induced lamellipodia. $a-c$, Low-magnification DIC images of a 1-d-old neuron with multiple branches before and 5 and $10 \mathrm{~min}$ after the application of $50 \mathrm{ng} / \mathrm{ml}$ BDNF. Lamellipodia were induced at multiple places along the neurite shaft as well as at the growth cone (arrows). $d$, A DIC time-lapse sequence of a portion of the neuron indicated by the dashed box in $c$ at a higher magnification. Numbers show the time (hours:minutes:seconds) after the addition of BDNF. BDNF-induced lamellipodia were very dynamic and were able to move along the neurite branches (arrows). Note the morphological changes resulting from the lamellipodial activity: the partial merge of two branches (arrowheads) and the increased number of new, thin lateral processes. $e, f$, To illustrate the morphological changes better, images of the neuron at the beginning $(e)$ and end $(f)$ of the time-lapse recording were processed using the trace contour function so that the outline of the neuron was visualized. As clearly shown in $f$, more complex morphology was observed after the BDNF treatment. 

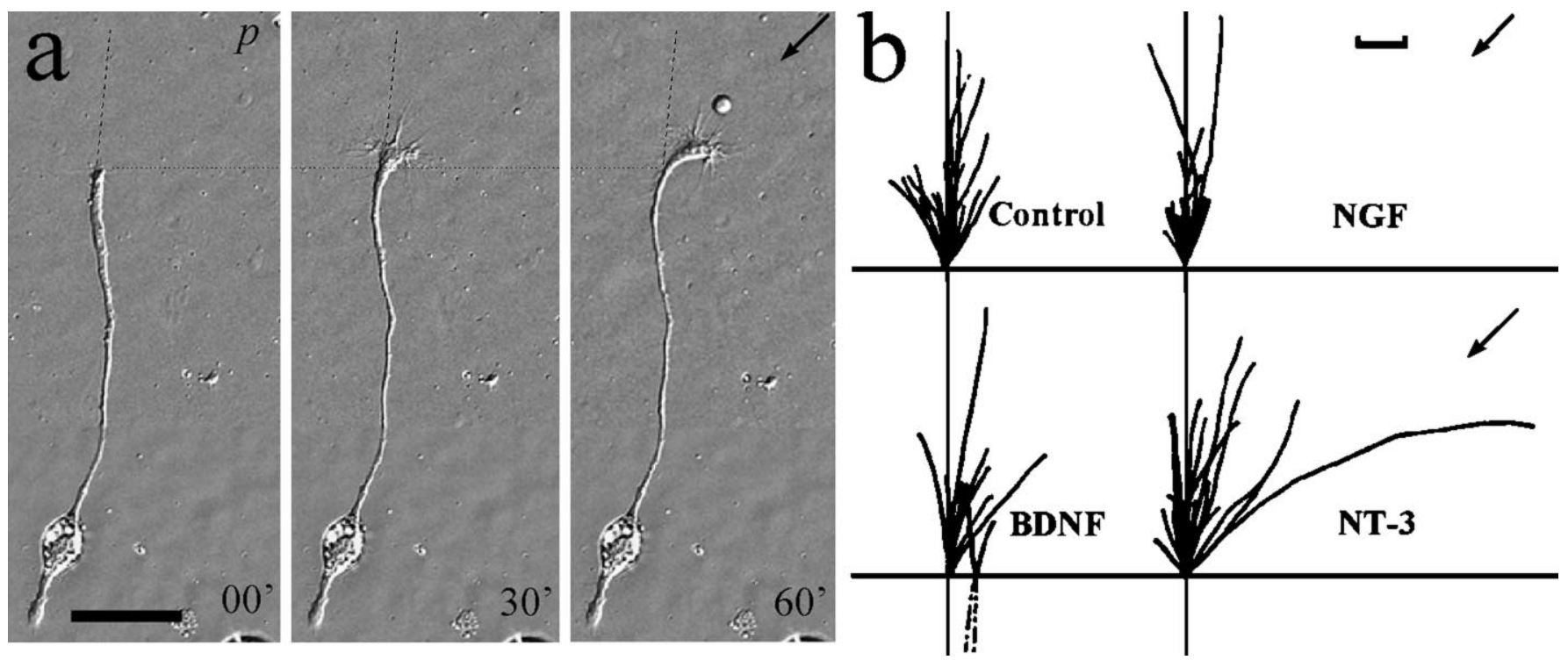

Figure 8. Turning response of 1-d-old Xenopus spinal neurons in the presence of neurotrophin gradients. $a$, Representative DIC images of a neuron at the onset and 30 and $60 \mathrm{~min}$ after the application of NT-3 gradient through a micropipette $(p)$. Scale bar, $50 \mu \mathrm{m}$. The dashed line indicates the original direction of neurite extension, and the dotted line indicates the corresponding positions along the neurite. $b$, Composite drawings of the path of neurite extension during a $1.5 \mathrm{hr}$ period for all the neurons in the absence (control) and presence of different neurotrophins (50 $\mu \mathrm{g} / \mathrm{ml})$. The origin represents the position of the center of the growth cone palm at the beginning of the $1.5 \mathrm{hr}$ experiment. The line depicts the trajectory of the neurite at the end of the $1.5 \mathrm{hr}$ experiment. The arrow indicates the direction of the gradient. The initial direction of neurite extension (defined by the distal $20 \mu \mathrm{m}$ segment of the neurite) was aligned with the vertical axis. In some cases the growth cone retracted slightly at the beginning of the experiment; for this reason some of the neurite drawings start with dashed lines. Scale bar, $10 \mu \mathrm{m}$.

Table 1. Response of Xenopus nerve growth cones to neurotrophin gradients

\begin{tabular}{|c|c|c|c|c|c|c|c|}
\hline \multirow{2}{*}{$\begin{array}{l}\text { Neurotrophin } \\
\text { in pipette }\end{array}$} & \multirow{2}{*}{$\begin{array}{l}\text { Concentration } \\
(\mu \mathrm{g} / \mathrm{ml})\end{array}$} & \multirow{2}{*}{$\begin{array}{l}\text { Turning } \\
\text { angle }\left({ }^{\circ}\right) \\
\end{array}$} & \multirow{2}{*}{$\begin{array}{l}\text { Net neurite } \\
\text { extention }(\mu \mathrm{m})\end{array}$} & \multicolumn{3}{|c|}{$\underline{\text { Turning responses }(\%)^{a}}$} & \multirow{2}{*}{$\begin{array}{l}\text { No. of cells } \\
\text { examined }\end{array}$} \\
\hline & & & & + & 0 & - & \\
\hline \multirow[t]{3}{*}{ BDNF } & 50 & $13.1 \pm 3.9^{*}$ & $14.1 \pm 1.8$ & 64 & 18 & 9 & 11 \\
\hline & 5 & $9.6 \pm 5.1$ & $19.8 \pm 2.2$ & 55 & 27 & 18 & 11 \\
\hline & 0.5 & $1.1 \pm 4.0$ & $10.2 \pm 1.1$ & 42 & 33 & 25 & 12 \\
\hline \multirow[t]{3}{*}{ NT-3 } & 50 & $13.0 \pm 4.8^{*}$ & $16.1 \pm 2.4$ & 63 & 25 & 13 & 16 \\
\hline & 5 & $9.7 \pm 4.5$ & $15.4 \pm 2.7$ & 55 & 36 & 9 & 11 \\
\hline & 0.5 & $3.2 \pm 3.5$ & $13.6 \pm 1.8$ & 40 & 40 & 20 & 10 \\
\hline \multirow[t]{3}{*}{ NGF } & 50 & $-0.5 \pm 2.5$ & $12.5 \pm 2.2$ & 33 & 33 & 33 & 12 \\
\hline & 5 & $1.3 \pm 2.5$ & $12.3 \pm 1.8$ & 27 & 55 & 18 & 11 \\
\hline & 0.5 & $3.1 \pm 3.4$ & $22.0 \pm 4.7$ & 36 & 36 & 27 & 11 \\
\hline Control & Medium & $-1.5 \pm 3.9$ & $13.0 \pm 1.4$ & 41 & 24 & 35 & 17 \\
\hline
\end{tabular}

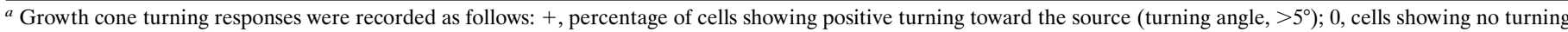
(turning angle, $<5^{\circ}>-5^{\circ}$ ); and - , cells turning away from the source (turning angle, $<-5^{\circ}$ ).

${ }^{*} p<0.05$ (ANOVA and post hoc Dunnett's tests).

Recent studies have shown that neurotrophins can induce sprouting of corticospinal axons in adult nervous system (Schnell et al., 1994) and can influence the pattern of dendritic development in visual cortical neurons (McAllister et al., 1995, 1996). In our $24 \mathrm{hr}$ embryonic Xenopus cultures some of the spinal neurons have already arborized to give rise to distinct branching patterns. Acute bath application of BDNF rapidly induced lamellipodia, which can change the morphology and branching pattern of the neuron (Fig. 7). Furthermore, an increased number of thin lateral processes that emerged from the main branches were observed after the BDNF-induced lamellipodial activity (Fig. 7). It is unknown whether these thin processes represent the precursors of mature branches, because long-term observations were not made. In theory, the BDNF-induced lamellipodia, if induced at the synaptic terminals, could also modulate synaptic connectivity by initiating new contacts between presynaptic and postsynaptic cells.

\section{Chemotropic guidance of growth cones by neurotrophins}

In the final part of our study, we showed that BDNF and NT-3, applied as concentration gradients, induce a chemotropic turning response of the growth cones, whereas the related factor NGF was ineffective. The neurotrophin concentration triggering growth cone turning in these experiments is similar to the effective concentration for increased survival and neurite out- 
growth (see above) and the effects on synaptic activity previously reported (Lohof et al., 1993). In the present study, the growth cones responded to a gradient of about $10 \%$ over a basal average neurotrophin concentration of about $50 \mathrm{ng} / \mathrm{ml}$ $(50 \mu \mathrm{g} / \mathrm{ml}$ in pipette). Although the present result appears to represent the response of the growth cone to the diffusible gradient of neurotrophin, we have not excluded the possibility that the neurotrophin binds to the glass substrate and the growth cone responds to this bound gradient. If this were the case, it would suggest that differing concentrations of neurotrophins binding to substrate cells could be a mechanism for growth cone guidance.

The growth cone turning induced by BDNF or NT-3 is unlikely to be the direct result of the growth-promoting effects of neurotrophins, because NGF promoted neurite outgrowth to a similar extent as BDNF (Fig. 2) but failed to produce a positive turning response. The intracellular events that mediate the neurotrophin-induced growth cone turning are unknown. The possibility that different signaling cascades mediate the turning and the lamellipodial activity is suggested by the fact that NT-3 was able to produce the positive turning response but failed to induce lamellipodia. This notion is further supported by the difference in calcium requirement for BDNF-induced turning versus lamellipodia formation; BDNFinduced turning seems to depend on the presence of extracellular $\mathrm{Ca}^{2+}$ (Song et al., 1997), whereas BDNF-induced lamellipodial activity does not (preliminary data not shown). Furthermore, the fact that NT-3-induced turning does not depend on extracellular $\mathrm{Ca}^{2+}$ (Song et al., 1997) suggests that attractive turning induced by BDNF and NT-3 may also be mediated by different signaling pathways. It would be interesting to examine how and where the two signaling pathways induced by BDNF and NT-3 converge to induce the similar changes in the direction of the growth cone extension.

These diverse yet independent effects of neurotrophins on developing neurons may be the results of multiple intracellular signaling cascades initiated by neurotrophins. Studies in other systems on NGF signaling have shown that many downstream events can follow NGF treatment and Trk activation. NGF treatment was shown to increase the activity of both cAMPdependent protein kinase and protein kinase C in PC12 cells (McTigue et al., 1985) and to produce rapid phosphorylation of cytoskeleton-associated proteins (Halegoua, 1987). Furthermore, NGF-dependent tyrosine phosphorylation activates a number of signaling molecules, including phospholipase $\mathrm{C}-\gamma$ (Vetter et al., 1991; Obermeier et al., 1994), PI-3 kinase (Ohmichi et al., 1992; Obermeier et al., 1993), and multiple serine-threonine kinases (Boulton et al., 1991). Although it is unclear whether all of the Trk-activated signaling systems are present locally at the growth cone, it is possible that the neurotrophin gradient produces growth cone turning via a complex intracellular signaling pathway involving multiple enzymes and the modification of many substrates.

In conclusion, we have shown that neurotrophins, in addition to their classical functions on neuronal survival and neurite outgrowth, exert various acute effects on the morphology and motility of cultured Xenopus embryonic spinal neurons. Uniform application of BDNF induced lamellipodial activity at multiple sites along the neurite as well as at the growth cone, resulting in changes in neuronal morphology. When administered as concentration gradients, both BDNF and
NT-3 caused the growth cone to turn toward the source. Together with recent findings on the effects of neurotrophins on axonal arborization, dendritic growth, and synaptic connection, our results suggest that neurotrophins may play an important role in neuronal development and synaptic formation in vivo. These acute effects of neurotrophins on neuronal morphology and motility may well serve as the cellular basis for the long-term effects of neurotrophins on neuronal growth and regulation.

\section{REFERENCES}

Aletta JM, Greene LA (1988) Growth cone configuration and advance: a time-lapse study using video-enhanced differential interference contrast microscopy. J Neurosci 8:1425-1435.

Bailey CH, Chen M (1988) Long-term sensitization in Aplysia increases the number of presynaptic contacts onto the identified gill motor neuron L7. Proc Natl Acad Sci USA 85:9356-9359.

Bailey CH, Kandel ER (1993) Structural changes accompanying memory storage. Annu Rev Physiol 55:397-426.

Barbacid M (1994) The Trk family of neurotrophin receptors. J Neurobiol 25:1386-1403.

Barbacid M (1995) Neurotrophic factors and their receptors. Curr Opin Cell Biol 7:148-155.

Barde YA (1989) Trophic factors and neuronal survival. Neuron 2:1525-1534.

Barde YA (1990) The nerve growth factor family. Prog Growth Factor Res 2:237-248.

Barker SA, Caldwell KK, Hall A, Martinez AM, Pfeiffer JR, Oliver JM, Wilson BS (1995) Wortmannin blocks lipid and protein kinase activities associated with PI 3-kinase and inhibits a subset of responses induced by $\mathrm{Fc}$ epsilon R1 cross-linking. Mol Biol Cell 6:1145-1158.

Berninger B, Poo MM (1996) Fast actions of neurotrophic factors. Curr Opin Neurobiol 6:324-330.

Boulton TG, Nye SH, Robbins DJ, Ip NY, Radziejewska E, Morgenbesser SD, DePinho RA, Panayotatos N, Cobb MH, Yancopoulos GD (1991) ERKs: a family of protein-serine/threonine kinases that are activated and tyrosine phosphorylated in response to insulin and NGF. Cell 65:663-675.

Bray D, White JG (1988) Cortical flow in animal cells. Science 239:883-888.

Chao MV (1992) Neurotrophin receptors: a window into neuronal differentiation. Neuron 9:583-593.

Cohen-Cory S, Fraser SE (1995) Effects of brain-derived neurotrophic factor on optic axon branching and remodelling in vivo. Nature 378:192-196.

Connolly JL, Seeley PJ, Greene LA (1985) Regulation of growth cone morphology by nerve growth factor: a comparative study by scanning electron microscopy. J Neurosci Res 13:183-198.

Connolly JL, Seeley PJ, Greene LA (1987) Rapid regulation of neuronal growth cone shape and surface morphology by nerve growth factor. Neurochem Res 12:861-868.

Davies AM (1994) The role of neurotrophins in the developing nervous system. J Neurobiol 25:1334-1348.

Davies AM, Bandtlow C, Heumann R, Korsching S, Rohrer H, Thoenen $\mathrm{H}$ (1987) Timing and site of nerve growth factor synthesis in developing skin in relation to innervation and expression of the receptor. Nature 326:353-358.

Dechant G, Rodriguez-Tebar A, Barde YA (1994) Neurotrophin receptors. Prog Neurobiol 42:347-352.

Desmond NL, Levy WB (1986) Changes in the postsynaptic density with long-term potentiation in the dentate gyrus. J Comp Neurol 253:476-482.

Ernfors P, Bengzon J, Kokaia Z, Persson H, Lindvall O (1991) Increased levels of messenger RNAs for neurotrophic factors in the brain during kindling epileptogenesis. Neuron 7:165-176.

Funakoshi H, Frisen J, Barbany G, Timmusk T, Zachrisson O, Verge VM, Persson H (1993) Differential expression of mRNAs for neurotrophins and their receptors after axotomy of the sciatic nerve. J Cell Biol 123:455-465.

Glanzman DL, Kandel ER, Schacher S (1990) Target-dependent structural changes accompanying long-term synaptic facilitation in Aplysia neurons. Science 249:799-802. 
Greene LA, Kaplan DR (1995) Early events in neurotrophin signalling via Trk and p75 receptors. Curr Opin Neurobiol 5:579-587.

Griffin CG, Letourneau PC (1980) Rapid retraction of neurites by sensory neurons in response to increased concentrations of nerve growth factor. J Cell Biol 86:156-161.

Gundersen RW, Barrett JN (1980) Characterization of the turning response of dorsal root neurites toward nerve growth factor. J Cell Biol 87:546-554.

Halegoua S (1987) Changes in the phosphorylation and distribution of vinculin during nerve growth factor induced neurite outgrowth. Dev Biol 121:97-104.

Hallböök F, Ibanez CF, Persson H (1991) Evolutionary studies of the nerve growth factor family reveal a novel member abundantly expressed in Xenopus ovary. Neuron 6:845-858.

Hallböök F, Ibanez CF, Ebendal T, Persson H (1993) Cellular localization of brain-derived neurotrophic factor and neurotrophin-3 mRNA expression in the early chicken embryo. Eur J Neurosci $5: 1-14$.

Henderson CE, Camu W, Mettling C, Gouin A, Poulsen K, Karihaloo M, Rullamas J, Evans T, McMahon SB, Armanini MP, Berkemeier L, Phillips HS, Rosenthal A (1993) Neurotrophins promote motor neuron survival and are present in embryonic limb bud. Nature 363:266-270.

Heumann R (1994) Neurotrophin signalling. Curr Opin Neurobiol 4:668-679.

Hyman C, Hofer M, Barde YA, Juhasz M, Yancopoulos GD, Squinto SP, Lindsay RM (1991) BDNF is a neurotrophic factor for dopaminergic neurons of the substantia nigra. Nature 350:230-232.

Ip NY, Yancopoulos GD (1995) Neurotrophic factors and their receptors. Prog Brain Res 105:189-195.

Isackson PJ, Huntsman MM, Murray KD, Gall CM (1991) BDNF mRNA expression is increased in adult rat forebrain after limbic seizures: temporal patterns of induction distinct from NGF. Neuron 6:937-948.

Kaplan DR, Stephens RM (1994) Neurotrophin signal transduction by the Trk receptor. J Neurobiol 25:1404-1417.

Kater SB, Mills LR (1991) Regulation of growth cone behavior by calcium. J Neurosci 11:891-899.

Kennedy TE, Tessier-Lavigne M (1995) Guidance and induction of branch formation in developing axons by target-derived diffusible factors. Curr Opin Neurobiol 5:83-90.

Klein R (1994) Role of neurotrophins in mouse neuronal development. FASEB J 8:738-744.

Knusel B, Hefti F (1992) K-252 compounds: modulators of neurotrophin signal transduction. J Neurochem 59:1987-1996.

Kotani K, Hara K, Kotani K, Yonezawa K, Kasuga M (1995) Phosphoinositide 3-kinase as an upstream regulator of the small GTP-binding protein Rac in the insulin signaling of membrane ruffling. Biochem Biophys Res Commun 208:985-990.

Kuffler DP (1994) Promoting and directing axon outgrowth. Mol Neurobiol 9:233-243.

Letourneau PC (1978) Chemotactic response of nerve fiber elongation to nerve growth factor. Dev Biol 66:183-196.

Lewin GR, Barde YA (1996) Physiology of the neurotrophins. Annu Rev Neurosci 19:289-317.

Lo DC (1995) Neurotrophic factors and synaptic plasticity. Neuron 15:979-981.

Lohof AM, Quillan M, Dan Y, Poo MM (1992) Asymmetric modulation of cytosolic cAMP activity induces growth cone turning. J Neurosci 12:1253-1261.

Lohof AM, Ip NY, Poo MM (1993) Potentiation of developing neuromuscular synapses by the neurotrophins NT-3 and BDNF. Nature 363:350-353.

Lu B, Yokoyama M, Dreyfus CF, Black IB (1991) Depolarizing stimuli regulate nerve growth factor gene expression in cultured hippocampal neurons. Proc Natl Acad Sci USA 88:6289-6292.

Lumsden AG, Davies AM (1983) Earliest sensory nerve fibres are guided to peripheral targets by attractants other than nerve growth factor. Nature 306:786-788.

Lundborg G, Dahlin L, Danielsen N, Zhao Q (1994) Trophism, tropism, and specificity in nerve regeneration. J Reconstr Microsurg 10:345-354.

Maisonpierre PC, Belluscio L, Friedman B, Alderson RF, Wiegand SJ, Furth ME, Lindsay RM, Yancopoulos GD (1990) NT-3, BDNF, and
NGF in the developing rat nervous system: parallel as well as reciprocal patterns of expression. Neuron 5:501-509.

Mason CA, Wang LC (1997) Growth cone form is behavior-specific and, consequently, position-specific along the retinal axon pathway. J Neurosci 17:1086-1100.

McAllister AK, Lo DC, Katz LC (1995) Neurotrophins regulate dendritic growth in developing visual cortex. Neuron 15:791-803.

McAllister AK, Katz LC, Lo DC (1996) Neurotrophin regulation of cortical dendritic growth requires activity. Neuron 17:1057-1064.

McTigue M, Cremins J, Halegoua S (1985) Nerve growth factor and other agents mediate phosphorylation and activation of tyrosine hydroxylase. A convergence of multiple kinase activities. J Biol Chem 260:9047-9056.

Menesini-Chen MG, Chen JS, Levi-Montalcini R (1978) Sympathetic nerve fibers ingrowth in the central nervous system of neonatal rodent upon intracerebral NGF injections. Arch Ital Biol 116:53-84.

Nieuwkoop PD, Faber J (1967) Normal table of Xenopus laevis. Amsterdam: Elsevier.

Obermeier A, Lammers R, Wiesmuller KH, Jung G, Schlessinger J, Ullrich A (1993) Identification of Trk binding sites for SHC and phosphatidylinositol $3^{\prime}$-kinase and formation of a multimeric signaling complex. J Biol Chem 268:22963-22966.

Obermeier A, Bradshaw RA, Seedorf K, Choidas A, Schlessinger J, Ullrich A (1994) Neuronal differentiation signals are controlled by nerve growth factor receptor/Trk binding sites for SHC and PLC gamma. EMBO J 13:1585-1590.

Ohmichi M, Decker SJ, Saltiel AR (1992) Activation of phosphatidylinositol-3 kinase by nerve growth factor involves indirect coupling of the trk proto-oncogene with src homology 2 domains. Neuron 9:769-777.

Parker PJ (1995) Intracellular signalling. PI 3-kinase puts GTP on the Rac. Curr Biol 5:577-579.

Patterson SL, Grover LM, Schwartzkroin PA, Bothwell M (1992) Neurotrophin expression in rat hippocampal slices: a stimulus paradigm inducing LTP in CA1 evokes increases in BDNF and NT-3 mRNAs. Neuron 9:1081-1088.

Ruit KG, Elliott JL, Osborne PA, Yan Q, Snider WD (1992) Selective dependence of mammalian dorsal root ganglion neurons on nerve growth factor during embryonic development. Neuron 8:573-587.

Sato M, Lopez-Mascaraque L, Heffner CD, O’Leary DD (1994) Action of a diffusible target-derived chemoattractant on cortical axon branch induction and directed growth. Neuron 13:791-803.

Schnell L, Schneider R, Kolbeck R, Barde YA, Schwab ME (1994) Neurotrophin-3 enhances sprouting of corticospinal tract during development and after adult spinal cord lesion. Nature 367:170-173.

Seeley PJ, Greene LA (1983) Short-latency local actions of nerve growth factor at the growth cone. Proc Natl Acad Sci USA 80:2789-2793.

Segal RA, Greenberg ME (1996) Intracellular signaling pathways activated by neurotrophic factors. Annu Rev Neurosci 19:463-389.

Segal RA, Takahashi H, McKay RD (1992) Changes in neurotrophin responsiveness during the development of cerebellar granule neurons. Neuron 9:1041-1052.

Small JV, Rinnerthaler G, Hinssen H (1982) Organization of actin meshworks in cultured cells: the leading edge. Cold Spring Harb Symp Quant Biol 46:599-611.

Smith SJ (1988) Neuronal cytomechanics: the actin-based motility of growth cones. Science 242:708-715.

Snider WD (1994) Functions of the neurotrophins during nervous system development: what the knockouts are teaching us. Cell 77:627-638.

Snider WD, Johnson Jr EM (1989) Neurotrophic molecules. Ann Neurol 26:489-506.

Song H-j, Ming G-1, Poo MM (1997) cAMP-induced switching in turning direction of nerve growth cones. Nature 338:275-279.

Spitzer NC, Lamborghini JE (1976) The development of the action potential mechanism of amphibian neurons isolated in culture. Proc Natl Acad Sci USA 73:1641-1645.

Stoop R, Poo MM (1996) Synaptic modulation by neurotrophic factors: differential and synergistic effects of brain-derived neurotrophic factor and ciliary neurotrophic factor. J Neurosci 16:3256-3264.

Tabti N, Poo MM (1990) Culturing spinal cord neurons and muscle cells from Xenopus embryos. In: Culturing nerve cells (Banker G, Goslin K, eds), pp 137-154. Cambridge, MA: Massachusetts Institute of Technology. 
Tanaka E, Sabry J (1995) Making the connection: cytoskeletal rearrangements during growth cone guidance. Cell 83:171-176.

Tapley P, Lamballe F, Barbacid M (1992) K252a is a selective inhibitor of the tyrosine protein kinase activity of the trk family of oncogenes and neurotrophin receptors. Oncogene 7:371-381.

Tessier-Lavigne M, Goodman CS (1996) The molecular biology of axon guidance. Science 274:1123-1133.

Thoenen H (1995) Neurotrophins and neuronal plasticity. Science 270:593-598.

Vetter ML, Martin-Zanca D, Parada LF, Bishop JM, Kaplan DR (1991) Nerve growth factor rapidly stimulates tyrosine phosphorylation of phospholipase C-gamma 1 by a kinase activity associated with the product of the trk protooncogene. Proc Natl Acad Sci USA 88:5650-5654.
Wennstrom S, Hawkins P, Cooke F, Hara K, Yonezawa K, Kasuga M, Jackson T, Claesson-Welsh L, Stephens L (1994) Activation of phosphoinositide 3-kinase is required for PDGF-stimulated membrane ruffling. Curr Biol 4:385-393.

Zhang L, Schmidt RE, Yan Q, Snider WD (1994) NGF and NT-3 have differing effects on the growth of dorsal root axons in developing mammalian spinal cord. J Neurosci 14:5187-5201.

Zheng JQ, Felder M, Connor JA, Poo MM (1994) Turning of nerve growth cones induced by neurotransmitters. Nature 368:140-144.

Zheng JQ, Wan JJ, Poo MM (1996) Essential role of filopodia in chemotropic turning of nerve growth cone induced by a glutamate gradient. J Neurosci 16:1140-1149. 